It is strange that Dr Forsvthe should ask why it takes the secretary of state a vear to determine an appeal under section 190 when the issues are so much weightier. Disciplinary proceedings may arise from a clash of personalities. Whatever the result of the current deliberations between the DHSS and the Joint Consultants Committee, the HM(61)112 or similar procedure would lose some of its unfairness if regional health authorities were stripped of their responsibilities, if only because they do not follow the fundamental principles of natural justice in which the accused consultant is told who his accuser is.

FELIX WEALE

Kent

1 Dawsen J. The Salage case: the wider issues, Br lled 7 $1986: 292: 944-5$

2 Anonvmous. The lessons trom the Savage inquirs. Br . Hed 7 $1986 ; 293: 285-6$

Authors' RePLY, - Some of the issues in $\mathrm{Mr}$ Weale's letter relate to a specific case, and it would be inappropriate to make any comment on the details of an individual matter about which $\mathrm{Mr}$ Weale appears to have knowledge.

I remain of the opinion that it would be difficult not to follow the procedure laid down in $\mathrm{HM}(61) 112$ in cases involving professional conduct or competence, or both, where the complaints are of a serious nature and could lead to dismissal or a final warning. The procedure set out in paragraphs $8-15$ is formal, legalistic, and costly, and the associated expenses will be incurred by any employer invoking the process regardless of his efficiency. The question of who holds the contract is therefore irrelevant. In comparison with that procedure the secretary of state's appeal is informal and straight forward, and it is a matter of concern to authorities that, after delays in setting up the hearing, it can take so long for the secretary of state to promulgate his decision.

I cannot accept $\mathrm{Mr}$ Weale's contention that the existing procedure is unfair in that the emplover is not bound to identify the person who makes the original complaint. The rules of natural justice provide that the individual should know the exact nature of the charge against him and what he has been called on to answer. The existing procedure does that. Many prosecutions are brought in the criminal courts against people who are convicted as a result of the evidence, but the original informant is never named or identified.

J M FORSYTHI

Souch Last Thames Regional Health Autherie

Bexhill on Sea

Susex IN $393 \mathrm{No}$

\section{Abdominal pain and disorder of coagulation}

Dr V Roy and colleagues (21 May, p 1460 ) rightly emphasise the importance of a non-invasive technique such as ultrasonography as an aid to diagnosis in patients presenting with acute abdominal pain.

We recently treated a 53 year old woman with end stage renal failure secondary to glomerulonephritis who was currently receiving continuous ambulatory peritoneal dialysis. She presented with acute abdominal pain and haemorrhagic peritoneal dialysis fluid. She had had amenorrhoea for more than 30 years. During the past year she had had a few transient ischaemic attacks secondary to atrial fibrillation and had therefore been treated with warfarin, which was closely monitored and kept in the therapeutic range. On examination she had noticeable abdominal tenderness in the left upper quadrant, but no mass was palpable. Rectal and vaginal examination showed no abnormalities, and the peritoneal dialysis fluid was sterile. On the left straight leg raising was not only limited but painful. Her prothrombin time was not unusually prolonged and was reported to be $2 \cdot 7$ times the control value, and within 24 hours after admission her haemoglobin concentration dropped from 77 to $62 \mathrm{~g} /$; a diagnosis of retroperitoneal haemorrhage was considered. A computed tomogram showed a retroperitoneal haematoma on the left side measuring $8 \times 11 \mathrm{~cm}$. She was, however, treated conservatively: warfarin was stopped and she continued with dialysis. On an outpatient basis the resolution of her haematoma was monitored by ultrasonography and she remained well.

We conclude that in diagnosing and managing acute abdominal pain a close liaison between the physician, surgeon, and radiologist is mandatory.

MUHAMMAD YAQOOB

R AHMAD

Regional Renal L'nit.

Roval Liverpeol Herpital.

Liverpool L $88 \mathrm{XI}$

\section{Vocational training in general practice}

Following the recent action by the Joint Committee on Postgraduate Training for General Practice (7 May, p 1320) the regional adviser and chairman of the general practitioner subcommittee in the North East Thames region have written to the chairman of the joint committee informing her of a resolution which was passed at the annual meeting of the executive council of the association of course organisers by 52 votes to 12

The association of course organisers expressed concern about the apparently unforeseen consequences of the unique action taken by the committee to enforce its stated standards in the North East Thames region. The damage to the reputations and prospects of trainees past, present, and future) in the region, the disastrous effect on recruitment to vocational training in the region, and the resulting implications for the standards of general practice, particularly in deprived inner city areas, are of major concern

The association has urged the committee to withdraw its sanctions in order to allow more appropriate action to be taken to resolve the situation.

PAUL SACKIN

Alconburs:

Cambridgenhire pl:17 5100

\section{Surgical closure of the back lesion in open neural tube defects}

The time is ripe for a new controlled trial of closure of myelomeningocele, but I doubt whether the recent report by Messrs G T Deans and V E Boston (21 May, p 1441) sheds much light on the subject. The authors argue against the need for closure on the basis that in 109 babies with lesions above L2 born between $196+$ and 1971 and undergoing early closure the cumulative survival to 1 year was 0.51 compared with 0.50 in 105 similar babies born between 1978 and 1985 whose lesions were not closed.

McLone et al found 0.95 survival to 1 vear in 200 unselected patients born since 1975 and operated on for myelomeningocele, of whom $35 \%$ had lesions at or above L1. Even if the fatalities had come from this subset the difference between the resulting (approximately) 0.85 survival and Messrs Deans and Boston's 0.50 is significant $(p<0.001)$. Charney et al found 0.92 or better survival to 10 months in infants with myelomeningoceles whether or not the back was closed early. "These differences indicate that there was some factor common to all the babies in Messrs Deans and Boston's series which, as late as 1985 , determined a heavy mortality not experienced in the United States. Within this excess mortality-which needs explanation-differences due to closure or nonclosure might pass unnoticed.

I agree that surgical policy may have little influence on the eventual development of hydrocephalus and the need for a shunt, but the authors do not discuss the important late complications of scoliosis and neurological deterioration due to a tethered spinal cord, against which early operation may be an important preventive measure. ${ }^{+}$

A NORMAN GUTHKELCH

Section of Neurosurgery

University of Arizona

Arizona 85724

1 Guthkelch AN. Aspects of the surgical management of myelomeningocele: a review. Dev Med Child Neurol 1986;28:525-32. McLone DG, Dias L, Kaplan W'E, et al. Concepts in the management of spina bifida. Concepts in P'ediatric Neurosurgen 1985:5:97-106.

Charney LB, Sutton LN, Bruce DA, et al. Myclomeningocelo newborn management: time for parental decision. Z Kinderchir 1983:38:90-3.

+ Reigel DH, MCLone DG. Mvelomeningocele: operative treat ment and resultim 1987. Comcepts in P'ediatric Viurosurgen $1988: 8: 11-50$

\section{Antidepressant drugs in the elderly}

Dr Anthony J Duncan and Professor A John Campbell (30 April, p 1230) have studied elderly patients on long term antidepressant treatment in a general practice. They found that patients who were taking antidepressants had an equal health state with those who were not, and there appeared to be no unwanted effects. They then made the inference that these people were being kept on antidepressants for too long.

It could be said that these patients are in their current state of health because of the use of antidepressants. The only patients who showed a reduced health state were those who were receiving antidepressants for a previous definite depressive illness. If anything this adds to the alternative hypothesis as we know that not all people respond to treatment.

The answers that the authors seek would come from prolonged study with the addition of patients who had been taking long term antidepressants and came off them and patients who should have taken antidepressants but did not. The development of measures of health state will allow us to do more of these studies in the future, and our understanding of depression in the elderly will then be enhanced.

T D S SEDDON

Otumectai Health Centro

Tauranga.

New Zealan

\section{Euthanasia}

Dr Roger Higgs (14 May, p 1348) touches on a point that $I$ mentioned in the council debate on euthanasia, but unfortunately this point did not appear in your report on the debate (14 May, p 1408).

Dr Higgs identifies as a "disturbing feature of the report" that it reads as if it has been written by people who have already made up their minds before gathering evidence. This is nowhere more blatant than in the section dealing with the crucial distinction between the active and passive taking of life. The report distinguishes between "an active intervention by a doctor to terminate life" and "a decision not to prolong life." In paragraph 98 of the report this distinction is stated plainly as if it were incontrovertable, but there is no 
acknowledgment, let alone explanation, of the philosophical debate about this crucial point.

As Dr Higgs says, the principle of double effect deserves a mention in this report. Once it is accepted that there is a distinction in moral terms between the active and passive taking of life one can produce an elaborate and well reasoned justification of our present easy conscience with withdrawing treatment while holding out against active intervention to terminate life. If this is not accepted one has to consider either that active euthanasia, like the withdrawal of treatment, can be morally acceptable or that withdrawal of treatment, like active intervention to terminate life, is morally wrong. Both are attitudes that doctors will find difficult to integrate with current practice.

It is a pity that the report did not take the opportunity to explore the important philosophical questions behind this distinction. The distinction may be a valid one in moral terms, but it would have been a better report had it contained the arguments behind this. As it is one could be left with the suspicion that this is a particular can of worms that the working party was not keen to open up lest it should lead to some uneasy answers.

J P'WIGHT

Northern (ieneral Hespital,

Sheificld S5 $7 \mathrm{AU}$

\section{Organs for transplantation}

Professor Geoffrey D Chisholm (21 May, p 1419) discusses the "required request" and "routine inquiry" methods of obtaining organs for transplantation.

Reservations about "beating heart donors" originate from the 1979 memorandum to the 1976 report of the conference of medical roval colleges. The report recommended that absence of response to tests for brain stem death may indicate a hopeless prognosis and is a helpful guide to discontinuing artificial ventilation. The memorandum, however, incorrectly equated that state with death itself on the basis that "by then all functions of the brain have totally and irreversibly ceased." There is ample evidence that this latter deduction was, and remains, untrue.

Relatives who refuse permission for organs to be removed because the patient "has already been through enough" may have greater insight into the situation than the doctors wanting to harvest the organs. The explanation of Professor Chisholm's observation that the results of kidney transplantation from cadavers have come closer to the results with live donations is that the cadavers have come closer to being live donors. We must distinguish clearly between those donors who will be dead after life support is stopped (from whom kidneys and eyes may usefully be taken) and those who are nearly dead (from whom hearts, lungs, livers, and pancreas can be obtained while they remain ventilated, perfused, and reactive). Relatives should be given the opportunity to give or withhold consent for either circumstance.

Some anaesthetists recognise the need to anaesthetise such "cadavers" for surgery and to paralyse them, so the option of anaesthesia for the donor should also be offered specifically to donors or relatives of donors. Prior consent from donors is by a donor card, and this should be rephrased to allow consent to be given for removal of organs either before or after withdrawal of life support. Such consent should be countersigned by the doctor who has explained the procedure.

Professor Chisholm is wrong when he writes that "a patient not on a respirator can never be a donor." It is not necessary to be a "beating heart" donor for one's corneas and kidneys to be of use. People who have deleted all except eves and kidneys from the organs listed on their donor cards in the hope that this will ensure that they are not used as "beating heart" donors have no such security at present. This wish should be included explicitly on the donor card.

David J Hil.L.

Addenbrexke's Hospital

Cambridge CB2 2QO

\section{Medical education}

Dr H J N Andreyev (7 May, p 1326) should have been taught basic scientific principles while he was at secondary school. I was fortunate in being taught under HE Armstrong's "heuristic" method. Instead of being told to "verify the gas laws" I was given apparatus and told how to measure the effect of change of temperature on the pressure of a gas confined to a constant volume and of changes of pressure on its volume when kept at a constant temperature. In such ways I learnt to do reproducible experiments, to distinguish a dependent from an independent variable, and to consider the variability of observation and the dangers of coming to a conclusion on inadequate data.

When I came to the wards and clinics I had to amass my own data in a world in which the data were changing constantly. The rules which seemed to apply to one patient might not apply to another, or even to the same patient at a different time. I had to amass empirical experience. Tenderness at McBurney's point usually suggests appendicitisbut once when it appeared without any of the other signs of appendicitis it turned out to be caused by a hydronephrosis which had ruptured while the patient was at rest in bed. I know of no general scientific principles which will allow you to make these distinctions. If there were any, life would be much easier.

Doctors are technicians; peculiar ones, I agree, and with a remarkable field of work. My contemporaries were fortunate, for a registrar's round rarely had more than five or six students around the bed. Grand rounds were show occasions at which only the clinical clerk had much of a look in. Practical teaching is usually better given by juniors than by consultants, unless the consultant has a special delight in teaching or acting a part.

(iEORGE DISCOMBE

Havwards Heath

W's Sussex RH16 IHH

\section{Obstructive uropathy}

Dr Kathleen Lyons and others (28 May, p 1517) state that dilatation is the hallmark of obstruction of the urinary tract. While this is widely accepted, it is not true.

Ormand in his report of retroperitoneal fibrosis comments on the almost normal appearance of the renal pelvis in a man with acute anuria, ' and this has been noted by other authors.' Similar appearances have been noted in obstruction by carcinoma. Lalli refers to the common appearance of undilated pelvicaliceal systems in retroperitoneal fibrosis. Davies suggested that the pelvicaliceal system in acute obstruction was not dilated, and this has been confirmed by recent ultrasound studies." A range of appearances has been described in obstruction caused by various diseases. " Appreciable dilatation of the pelvicaliceal system and ureters may be present (especially in pregnancy) with no obstruction."

Ultrasound is not good at detecting dilatation of the pelvicaliceal system and is subject to false positive and false negative errors. "'" Enthusiasm for a new technique which is painless, easy, and relatively fast have made ultrasound investigations popular. Failure to follow a sequential series of investigations has been a factor.
In all medical practice it is important to understand the disease. Ultrasound is an imaging technique which shows anatomy and not physiology. It was predictable that it would be less than perfect in investigating many cases of obstruction. The duty of the radiologist is to understand the disease process and choose the most suitable imaging technique or sequence to elucidate the problem. It is too easy for ultrasound studies to become routine examinations which do not contribute to the diagnosis. ${ }^{1}$

PETER DAVIFS

Department of Radiology,

City Hospital,

Nottingham $\mathrm{N}(\mathrm{B} 10)+\mathrm{F}(\mathrm{i}$

I ()rmand JK. Bilateral ureteric ohstruction due to envelopment and compression by an inflammatory retroperitoneal process. 7 l'rol 1948;59: 1072-9.

2 Saxton HM, Kilpatrick FR, Kinder CM, Lessof MN, McHardy Young S, W'ardle DFH. Retroperiteneal fibrosis. $2.7 . \mathrm{Med}$ 1969:38:159-81.

SElliott S, Davies P. The urographic appearances of ureteric obstruction secondary to bladder carcinoma. Clin Radiol 1986:37:495-8

+ Lalli $\mathrm{AF}$. Retroperitoneal fibrosis and inapparent obstructive uropathy. Radiolog, 1977:122:339-42

Davie P. Lrographic appearances in renal failure due 10 inerape intraluming

6 Hill MC, Rich JL, Mordiat JG, Finder (CA. Sonography versus excretion urography in acute flank pain. American foumal of Rocingenology 1985;144:1235-8

Laing $\mathrm{F} C$, Jeffrey $\mathrm{BR}$, Wing VW. Ultrasound versus excretion urography in acute flank pain. Radiologv 1985:154:613-6.

8 Minford J. Davies P. The urographic appearances in acute and chronic retroperitoneal fibrosis. Clin Radiol 1984;38:51-7

Daties P. Ultrasound dees not diagnose ureteric obstruction. $7 R$ Sir Med in press

10 Talner L, Scheible W' Lillenbogen PM, Berk CH, Gosink BB How accurate is ultrasonography in detecting hydronephrosis in azotemic patients? ['rol Radiol 1981:3:1-6.

11 Amis IES. Cronan JJ, Pfister RC, Yoder IC. Ultrasonic in accuracies in diagnosing renal obstruction. Erologv 1982;19. $101-5$

12 Anonvmous. Diagnosing obstruction in renal failure. Lancel $198+$ :ii: $848-9$.

13 Mindel S. The full potential of ultrasound. Br.Med F 1988:296:

\section{Drug and alcohol misuse in pregnancy}

Dr Nabeel D Sulaiman and others (28 May, p 1500) found that $2 \%$ of a sample of 901 women in early pregnancy consumed $100 \mathrm{~g}$ or more absolute alcohol a week. The psychiatric department at Guy's Hospital recently set up a service within the antenatal clinic for pregnant drug addicts. To gauge some idea of the size of the problem we decided to carry out a random screening. On their initial visit to the antenatal clinic 218 pregnant women were asked to give urine samples. The purpose of the test was explained and verbal permission sought from each patient. Only two women refused; one of them later consented but no drugs or alcohol were found in her urine sample.

Of the remaining 216 women, four had positive results for alcohol, two for opiates, and one for benzodiazepine. Apart from one woman with epilepsy who was taking prescribed phenobarbitone, no other sedative or stimulant drug was detected in the urine samples. All four women who showed alcohol in their urine were over 30 . The urine test was sensitive to a blood alcohol concentration of $2 \cdot 2 \mathrm{mmol} / 1(10 \mathrm{mg} / 100 \mathrm{ml})$. Thus women who consumed alcohol before or during lunch or had drunk heavily the night before were detected. These patients may correspond to $\mathrm{Dr}$ Sulaiman and others' category of women who consume 10 or more standard drinks $(100 \mathrm{~g})$ a week. If so our findings are nearly identical. Only one of the four women agreed to be interviewed by a psychiatrist, and she claimed abstinence despite her results.

Both women with opiates detected in their urine were under 30 . They both accepted treatment and were using less than $20 \mathrm{mg}$ heroin a day. One smoked and the other injected heroin intra- 